\title{
Systems Education for a Sustainable Planet: Preparing Children for Natural Disasters
}

Kevin R. Ronan ${ }^{1}{ }^{*}$ and Briony Towers ${ }^{2}$

1 School of Health, Human and Social Sciences, CQ University Australia, Rockhampton, QLD 4701, Australia

2 School of Mathematics and Geospatial Science, RMIT University, Melbourne, VIC 3000, Australia; E-Mail: briony.towers@rmit.edu.au

* Author to whom correspondence should be addressed; E-Mail: k.ronan@cqu.edu.au.

Received: 29 November 2013; in revised form: 3 January 2014 / Accepted: 15 January 2014 /

Published: 24 January 2014

\begin{abstract}
This paper first reviews research linked to the United Nations International Strategy for Disaster Reduction focusing on "child-centred disaster risk reduction" (CC-DRR), highlighting systemic aspects of disaster prevention and preparedness educational programming to date. However, it is also pointed out that education evaluated to date largely assumes a linear, mechanistic approach to preparedness and related resiliency outcomes. Thus, the main thrust of this paper is to elucidate means by which hazards and disaster preparedness education programs for children can shift to systems-based models, those that incorporate both systemic epistemologies but also more systems-based, and interconnected, curricula. This includes curricula that help children connect the physical world and science with the social world and human factors. It also includes the more systemic idea that natural hazards are but one example of a larger category of problems in life related to risk and uncertainty. Thus, a main aim of a systems educational approach is to help children equip themselves with knowledge, skills, motivation and confidence that they can increasingly manage a range of risks in life. This includes an increasing understanding of the added value that can be gained from approaching problems with systemic tools, including producing increasingly effective and sustainable solutions to what public policy refers to as wicked problems.
\end{abstract}

Keywords: disaster prevention and preparedness; systems education; children and youth 


\section{Introduction}

In systems thinking, physical and the social worlds are treated as interconnected. In education in the Western world, academic subjects are treated largely in isolation [1]. This includes the subject of natural hazards and disasters [2]. Amongst other things, a split often exists between the physical systems linked to naturally occurring events and the social systems that are connected to their anticipation, occurrence and aftermath [3]. What follows in this paper is first a selective review that starts within the social system, namely "hazards education" programs for children and youth. More specifically, following some background for context, it starts with the notion of a fairly specific type of hazards education for children and youth, that of disaster resilience education done during the "prevention and preparedness" phase of the disaster cycle (i.e., before a disaster's occurrence). A main aim of these programs for youth is to increase young people's resilience to disasters, helping them to prepare so that they, and their families, might respond and recover more effectively. As the review aims to demonstrate, while there are seeds of systems-based thinking and education within this area, it is largely underpinned by a linear, mechanistic model that tends to treat interconnected problems in isolation or simply ignore them.

\section{Promoting Preparedness for Disasters in Youth}

In an attempt to reduce the impact of hazardous events, published research since about the turn of the century [4,5] has begun to focus on hazards and disaster education programming for children. It is a well-established finding that households and communities typically do not attend to prevention and preparedness, including recommended risk reduction activities and safety measures [6]. This low rate of documented preparedness in households and communities includes for those in vulnerable groups in a community and in established high hazard areas (e.g., for earthquakes including San Francisco Bay Area; and Wellington, New Zealand) [3,7].

Additionally, in terms of youth themselves, research has demonstrated that larger scale hazards create vulnerability for children. For example, research on childhood fears has consistently found that the most feared situations for children tend to vary across age groups. However, some fears tend to be stable across age groups, particularly those that reflect threats to survival. Thus, research in the 1980s [8,9] found that of the eight most feared situations across 8-17 year-olds, a number of them were related to natural or man-made disasters, either directly (earthquakes; bombing attacks; fire-being burnt to death) or indirectly (not being able to breathe; falling from a high place). In addition, in the aftermath of a disaster, children tend to have more intense fears including of the same or other disasters occurring. For example, when asked an open-ended question about fears they or children their age have, children who were both exposed and not exposed to Hurricane Katrina named future hurricanes or tornadoes [10].

Following a disaster, children have also been identified in a large scale review as the most vulnerable demographic group for severe reactions [11]. Even in a relatively benign hazard, a significant minority of children have been found to have moderate to more severe reactions. For example, after a series of volcanic eruptions, where there was no loss of life, over $10 \%$ of a sample of 118 schoolchildren met the self-reported criteria for acute and post-traumatic stress syndromes [12]. 
In addition to children being cited as a particularly vulnerable sample, the Norris et al. review [11] also identified families with children as another vulnerable group. It is also worth noting that one of the strongest risk factors, if not the strongest, for a child having negative reactions to a hazardous event is a parent's reactions [13-15]. Linked to this idea, children with emotional and behavioral difficulties tend to have parents with similar problems (e.g., anxiety) [2,3]. A final link here is that these factorsemotional, behavioural, decision-making/problem-solving — are systemically related to each other. For example, parents of anxious and aggressive children have been found to reinforce unhelpful problemsolving strategies (avoidant and aggressive, respectively) [16]. In another study, parents of anxious children were also rated as less granting of autonomy to their child, perhaps linked to a tendency also found in parents of anxious children to be over controlling or overprotective [17].

Such findings have underpinned moves to reduce vulnerability in children and families, before, during and after a hazardous event [2,3]. The focus in this article is on risk reduction through pre-disaster prevention and preparedness education programs aimed at reducing vulnerability through reducing risk while increasing physical and emotional preparedness. In addition to reducing vulnerability, another rationale for these programs is that today's youth are tomorrow's adults. However, in more current discussions, children are also a source of enthusiasm and motivation that potentially can help mobilize households and communities to act. This is important in light of the findings that show convincingly that community preparedness is low and further suggest motivation to be a central problem e.g., [18-21].

\section{Disaster Preparedness Education: What Do We Know Thus Far?}

A recent review ([22], see also [3]) suggests that school-based preparedness programs can assist to increase motivation and actual preparedness [23,24]. For example, an early cross-sectional study [4] examined the effect preparedness education had on a number of factors in a reasonably large sample of schoolchildren $(n=460)$. Participation in a preparedness education program was related to more realistic perceptions of risk and increased knowledge of appropriate safety behaviours. Another finding was that children who participated in preparedness programs also reported lower levels of fears in relation to hazardous events compared to children who had not participated. These children also were less likely to perceive their parents as having hazards-related fear.

Another study [5] also found that participation in preparedness education programs is related to a number of benefits, including replicating a number of findings of the first study. Additionally, the study found that children who reported involvement in a preparedness program, versus those who were not involved in a program, reported more preparedness activities at home as did their parents. That study also empirically identified predictors of increased preparedness activities including: (1) involvement in more recent and a greater number of preparedness programs; (2) more knowledge of risk reduction activities and safety behaviours; and (3) more interaction at home (i.e., discussions between children and parents) linked to learning in a preparedness program. More recent cross-sectional [25] research has extended earlier findings.

In addition to correlational research, experimental findings have also supported the value of education programs increasing resilience indicators [23,26,27]. For example, the first of these used a quasi-experimental design with classrooms randomly assigned to one of two conditions. The first was 
based on usual school curricula, focused on a reading and discussion format about special topics, the topic here being disasters. The second condition added a more specific emergency management focus to the reading and discussion format. This included specific discussions and activities focused on preparedness activities that youth could do independently or with parents. One exercise was a homework activity designed to be done with parents to encourage a number of specific preparedness activities. In terms of findings, both the usual conditions (UC) and emergency management-focused (EM) programs led to significant benefits on a number of indicators. In terms of knowledge and home-based preparedness activities, the EM condition was seen to significantly out-do the UC condition. In terms of emotional factors, both the EM and UC conditions led to benefits and did not differ from each other. Given that both conditions led to changes suggests that preparedness programs don't by themselves raise fears and, further, can be beneficial [2]. These experimental findings [26] have also been replicated and extended [23].

Given findings overall in this area based on a recent systematic review [23], there is evidence-based promise for children's involvement in hazards education programs, albeit in a limited number of studies, a number of which have limited methodologies [22]. Despite that issue, preparedness education programs that involve children appear to be increasingly common globally, endorsed by the United Nations International Strategy for Disaster Reduction (UNISDR) as part of a "child-centred disaster risk reduction" (CC-DRR) emphasis. As confirmation of increasingly widespread CC-DRR activities, a recent UNESCO and UNISDR supported mapping exercise reported on and described preparedness programs across 30 countries [28]. While most programs to date do not have accompanying research findings, they do appear to have potential based on the research that has been conducted. As a most recent illustration to highlight the potential, a recent study [27] used a quasi-experimental and benchmarking design and methodology and found an increase of 6 parent-reported home-based hazard risk reduction activities. Children were found to increase their hazards-related knowledge by $39 \%$. These increases were after a quite brief four session interactive preparedness program held at a youth centre. It is worth noting that this study was done with a sample from a lower SES stratum, including about half of the youth involved not being engaged with education or vocational training. Given that SES is a major risk factor for poor adjustment to a disaster [11,29], disaster preparedness programs for children and youth have increasingly documented potential as a gateway for increasing resilience in some of the most vulnerable sectors of a community.

\section{Moving to a Systems Focus}

Some of the findings to date in disaster preparedness education implicate systemic features, including education involvement and increased knowledge being linked to lower fear levels [4,23,26,27] but also linked to greater risk perceptions about injuries [4] and more frequently occurring events [25]. This finding implicates systemic relationships between factors that are sometimes thought about in simpler cause-effect terms. For example, in focus group research, some teachers have expressed concerns that exposing children to hazards-related risk information might raise both children's concerns about risk and, in doing so, scare them [30]. In children as young as 7, exposure to hazards risk information in an education program actually has been shown to produce increased accurate knowledge and increased risk perceptions (e.g., increased perception of risk of injury). However, in 
contrast to teacher focus group perceptions, multiple studies have demonstrated that these same children also report significantly reduced levels of fear in relation to those hazardous events compared to those who have no exposure to risk information [4,23,26,27]. Further yet, there is an additional correlational link that has been found between increased knowledge (or search for knowledge) and increased action, including increased preparedness activities done at home [5,26] (and an increased sense of control in relation to preparedness [27]). Thus, starting at a relatively early stage of development, children have been shown to be quite capable of learning about risk in ways that promote emotional and physical resilience. Another of the findings here implicating systems features is the notion that children can take a preparedness mindset with them into the home setting to promote further benefits. A cross-sectional study done in Japan further demonstrates this potential, linking children's learning not only to the home but also to larger community benefits [24].

On the other hand, disaster preparedness education for children to date largely rests on notions that child- and home-preparedness is the "royal road" in preparedness terms. Another is that education programs themselves can often be quite simple and revolve around the theme of a "disaster as a discrete event that leads to potentially destructive effects that child-, school- and home-based preparedness will mitigate" linear sequence [23]. From a systemic view of disasters (and of risk more generally) [31,32], this sequence just simply does not account for the complexities involved in disasters. That is, disasters are an example of what public policy might refer to as a "wicked problem" [33]. To illustrate first systemic issues in disasters, two examples are provided in relation to floods and fires, respectively. Then, in subsequent sections, consideration of the building blocks necessary to help children begin to develop the increasing capacity to solve these sorts of complex challenges is taken up.

Starting with examples of disasters as wicked problems, and firstly in relation to floods, a common mitigation measure in populated areas is levee construction [34]. However, a lack of systems thinking has invited a number of problems with this mitigation measure. In what is called the "levee syndrome", the building of levees may protect an area from a flood event. However, even if it does, the water eventually will have to go somewhere. Thus, there are many documented occurrences where farmers' and others downstream from a levee site get inundated [2]. Another problem with such a mitigation measure is related to an implicit idea that humans can control nature. In the case of a levee, they tend to be built to withstand certain intensity flood events (e.g., 100 year floods). Thus, when an event exceeds the planned capacity (e.g., a 1000 year flood), or if the levee is engineered poorly, the levee itself will be overwhelmed [34]. A corollary of this "humans can control nature" theme is that the building of levees can give the impression that it is safe to live in the area. Thus, the building of levees can invite increased building, settlement and populations. When a levee fails, it can then further lead to a host of problems that are not anticipated [34].

In the case of bushfires, to cite an example from Australia, analysis done by Brian Ashe, John McAneny and colleagues at Risk Frontiers at Macquarie University, shows the value of a systems approach. First, since 1900, fires in Australia have stayed relatively constant in terms of frequency, intensity, spread. Loss of life has also stayed fairly constant, as have other factors (e.g., risk of losing houses). Loss of life from bushfires is currently at rate of 14 per annum (low by international standards) [35], far less than some other fatality risks (e.g., structural fires, 100 per annum; road fatalities, 1600 per annum) [36]. The relatively low rate of fatalities and other losses is despite increased population and related infrastructure (e.g., homes, buildings) in areas of high bushfire risk. 
A main reason appears to be that public investment in risk mitigation procedures has increased significantly over time. However, the cost effectiveness of current investment has been questioned, including by experts engaged in a "structured expert judgement exercise" [35]. Experts all agreed that there was no net benefit from increasing investment and most indicated that reducing the investment would yield increased net benefits. Interestingly, as politicians and others might point out, over-investment should not be a problem if lives are saved. However, systems analysis shows that "compliance with costly government interventions affects the consumption of risk-reducing goods and services in the same way as a decline in wealth" (p. 2) [35]. Such a reality is also not going to assist people becoming motivated to prepare, including a perception that large-scale government investment in risk mitigation is largely going to fix the problem. The current investment itself has been attributed at least in part to public perceptions, where the public has been found to over-estimate bushfire-related fatalities and these perceptions then having a knock-on effect to political and policy decisions affecting funding [36]. Finally, a study benchmarking Australian investment in risk mitigation against 11 other countries showed no significant relationship between government spending and losses from fire. This suggests other factors are responsible, including human settlement patterns [37]. In fact, one of the reasons for increased problems linked to a range of hazardous events, including floods and bushfires, is increasing human settlement and development (In the case of volcanoes, the problem has become such that an entire conference series starting in the shadow of Mt. Vesuvius (Naples) in 1998 - Cities on Volcanoes - deals directly with the problem of increasing human settlement worldwide in areas vulnerable to volcanic eruptions).

This includes through policies that do not deter settlement but in fact subsidise settlement in a sense through government rather than household-financed risk mitigation and response costs. This includes both costs in anticipation (e.g., prevention measures) and costs in response (e.g., firefighting resources; compensation to victims) [37]. Contrast the investment in bushfire risk mitigation with the situation in relation to structural fire losses. Research shows that for structural fires, most of which are residential fires, those who experience them tend to be some of society's most vulnerable populations (e.g., from the lowest SES strata) who reside in accommodation with higher levels of fire risk [38]. However, despite increased fatalities linked to structural fires, this problem gets less attention than does bushfires, in both research and in the media. In Australia, the risk of dying in a structural fire is seven times that of dying in a bushfire. Thus, overall, it appears that risk mitigation in terms of government investment in reducing fire risk tends to be unequally distributed across a society, raising social issues (e.g., equity) [36].

Nevertheless, risk reduction education campaigns and programs are encouraged and promoted in both bushfire and urban locations (where residential fires are more common). However, as is found in other countries and for other hazards, preparedness for fires is generally quite low, implicating low motivation. As pointed out by Ashe and colleagues [36], the motivation to engage in increased safety behaviours may be not be high in either setting, but for different reasons. High government subsidy in bushfire prone areas may reduce a sense of increased personal responsibility (In the case of bushfires, while average annual deaths in Australia average 14 per year, catastrophic fires lead to spikes in the form of increased deaths and destruction. The main risk factor in these instances appears to be proximity to bushland, either being within bushland itself or in very close proximity (within $10 \mathrm{~m}$ ) [39]. One implication of this finding is that creating a perimeter around a home by clearing bush is 
advantageous for saving lives and property, particularly when, as is quite commonly the case, land use planning policies are deficient and government subsidises risk by heavy investment in both costs in anticipation and costs in response [36]).

In structural fire prone areas, other more pressing daily living requirements may reduce a sense of urgency about fire safety ([38]; see also [36]). In addition, even if mitigation measures are available in residential settings, they may not help. For example, in a study looking at residential fires in Surrey, British Columbia [40] while one third (36\%) of residences that experienced fires did not have smoke alarms, the rest did. However, of those 1,554 residences that did have alarms, almost half (49.5\%) were not activated during the fire. Further yet, various factors are known to militate against appropriate response to smoke alarm activation (e.g., young and old age; impairment and disability; being asleep) [40]. In addition, a smoke alarm may provide an illusory sense of control that then proves a deterrent to additional prevention and safety behaviour in the home (e.g., related to acquiring information about how to prevent and mitigate risk in relation to the known causes of residential fires including factors mostly related to human negligence including cooking-, open flame-, smoking-related factors and others [36,40]. These examples could continue to be elaborated (Examples will be returned to in subsequent sections to highlight ways that education programs for children might help them consider ways to solve some of the problems considered in this section).

However, the point here is to illustrate that preparedness and disaster preparedness education for children will benefit from a more holistic perspective. One that links physical with social systems more effectively and helps them begin to understand that problems related to risk reduction and increased preparedness are not based on a simple cause and effect approach but rather based on a range of physical and social factors that are interconnected. To anticipate later discussions, it is worth pointing out that children at younger ages have not developed the cognitive capacity to think in adult, or systemic, terms. For young children entering school, this will include a focus on appealing to their lifeworld and their level of development, focusing on simple knowledge and linking that to preparedness understanding and activities aimed at keeping them and important people safe. Over time, this foundation can be built on as children's development takes on more cognitive complexity and moves from a more purely egocentric view to one that increasingly incorporates, and can accommodate, more systemic, civic, and abstract concepts and views of life [41].

\subsection{A Systems Educational Approach}

As reviewed in a previous section, research supports the value of disaster preparedness education in changing risk perceptions, knowledge and behaviour, as reported by children and their parents. However, research to date has focused mainly on standalone education programs that themselves are focused more singularly on disaster awareness and preparedness. The two forms of preparedness generally emphasized are child and family safety behaviours as well as home-based risk mitigation activities. This is as opposed to an educational approach that has disaster preparedness as one part of a an interconnected model of education and incorporates but also goes beyond safety behaviour and risk mitigation activities. An approach that embeds disaster preparedness education as part of a larger focus on helping children understand their worlds from a holistic ontological, epistemological and scientific perspective: One that links learning in one sphere (disaster risk reduction) to larger 
organizing themes and that becomes increasingly interconnected over time. In current views around the philosophy of science and its disciplines (including education), whereas Pepper [42] discussed four traditions (formism, contextualism, mechanismic, organismic), some current models have collapsed across these four and now emphasise two: split versus relational models [43].

Thus, emphasizing a relational (organismic-contextual) philosophical and educational approach, one premise related to this mindset is that disaster preparedness education can be seen merely as one smaller part of a larger theme of helping children develop capacity (i.e., knowledge and skills) to understand, accept and manage risk and uncertainty in life more generally. Thus, the idea underpinning the organizing theme of "understanding and managing risk and uncertainty" here is linked to a relational philosophy, where education is able to help children make connections between topics that are typically more siloed. This includes through introducing a systemic way of thinking and processing information but also includes the content of courses themselves. Preparedness and the management of risk also implicate a systemic relationship between learning, emotions and behaviour, including motivational factors. What follows are sections devoted to these factors, starting with an overview of the how and what of these programs.

\subsection{The How and What of a Systemic Approach to Education: Process and Content}

The first of the factors introduced just above, systemic thinking processes focuses on the "how", or the means underpinning a systems view of the world. Thus, the idea here is to help children develop the tools, and an increasingly differentiated capacity, to understand and manage risk and uncertainty, including effective disaster preparedness and risk reduction. Various approaches are available from different disciplines. From environmental science, one scheme focuses on dealing with problems through development of "cognitive interdisciplinary skills" linked to science education [44]. Another set of approaches focus on using problem-solving approaches. One of these schemes, drawn from a social science perspective, deals with problems through primary versus secondary appraisal and problem-solving skills [45]. Another problem-solving model is drawn from an educational perspective and focuses on inclusive and evolutionary themes [46]. In addition to systemic thinking processes, more interactive educational models that stress experiential and enactment learning are recommended $[2,47]$. Through "seeing, learning, practicing and doing" [2], cognitive and affective learning within a social context can be emphasized, including the connections between thinking, feeling and behaviour in the world (e.g., mastery links to feelings of well-being; knowledge about and approaching feared objects or problems tends to reduce anxiety; talking with others about problems can help solve problems and help one feel supported).

One form of learning introduced earlier that might be particularly emphasized is framing hazards and risk as community-based "problems to be solved" versus insurmountable threats. In fact, presenting problems as "challenges versus threats" has a good deal of empirical support [48]. The main idea here is that emotional factors link directly to problem-solving capacities. Challenge appraisals promote facilitative feelings and arousal configurations that promote "approach" behaviour; threat perceptions promote more avoidance. Thus, when one is motivated versus scared and feels a problem does have potential solutions, it is then more likely that s/he can recruit physiological and cognitive processes that lead to successful task performance [48] (According to Blascovich and colleagues [49], 
challenge versus threat appraisals are related to the balance between perceived resources and demands one experiences in dealing with any stressful event: "When perceived resources exceed perceived demands, a state of challenge is invoked. Challenge states are typically associated with better performance, positive affect, and, importantly (in the context of potential responses to in-group deviants), a heightened desire to approach positive goals actively (for reviews, see [50,51]). Conversely, when demands exceed resources, a state of threat is typically invoked. Threat is associated with negative affect, limited focus, and a state of approach or avoidance [48]. Challenge and threat represent opposite ends of a continuum, such that relative differences in challenge and threat (e.g., greater vs. lesser challenge) are meaningful. Changes in the balance of resources and demands affect neural and adrenal pathway activation (specifically, sympathetic adrenal medullary and pituitary adrenal cortical axes activation; see [48] for a thorough review). Activation of these pathways leads to distinctive patterns of cardiovascular responses that are used to index challenge and threat, respectively." (p. 106).

Thus, in helping children mobilize inner resources that help them approach versus avoid risks, this includes helping them develop a sense of control and "agency", the sense that "I can do this, I can solve this problem." Thus, from a very young age indeed, longitudinal research demonstrates that children's sense of agency (self-efficacy) can be raised or lowered through healthy approach coping environments versus more threat-based environments. For example, in a study of predictors of toddler self-efficacy, greater maternal behaviours (acceptance; responsiveness) at 5 and 17 months of age predicted greater self-efficacy behaviours at 17 months whereas greater maternal anxiety predicted decreased self-efficacy behaviours [52]. Similarly, school settings can promote risks as problems to be approached and as challenges to be solved.

In addition to the process (or "how") of a more systemic approach to preparedness education, there is also the content itself (the "what"). As inter-disciplinary process knowledge and skill development can help children develop the ability to connect the physical and social worlds so too can the manner of presenting the educational content itself. Thus, moving disaster preparedness education from one off, standalone programs to that which is embedded across curricula is the theme here. One that integrates both horizontally and vertically [47]. Such integrated curricula then has potential to help children acquire knowledge in a given area while gaining an increasing understanding of the world from a more connected perspective (As an aside, it is worth pointing out that even in standalone disaster resilience education programs, where risk reduction and preparedness are the main themes, there is room for increased connectedness).

Main themes in a more integrated curriculum would include helping children [2]:

(1) To understand the science related to hazards and risk - knowledge has been linked to promoting reduced fear and increased approach coping (e.g., home-based risk reduction activities);

(2) To build systemic problem-solving capacities for managing hazards and risk;

(3) To build motivational and emotional competencies necessary to solve problems related to risk, including seeing hazards, risk, and uncertainty as individual and community-based challenges versus threats. 


\subsubsection{A Systemic Educational Approach: Understanding Science, Developing Capacity}

Drawing on current models of education that can be linked to reducing risk and increasing preparedness in relation to disasters, various approaches are possible to draw from [53] including the following:

- The Earth-System-Science (ESS) Model [54,55];

- Holistic disaster preparedness and resilience educational models [2,29,47].

Developed by the NASA Advisory Council's Earth System Science Committee [54], the ESS model has three main themes [55]:

- Earth and its place in the universe;

- Earth systems;

- Earth in relation to human activities.

And, three steps to connect these themes:

- Step 1: Understanding the four earth systems in terms of the "spheres" (atmo, bio, hydro, litho);

- Step 2: Add an event (e.g., natural hazard);

- Step 3: Tools to develop understanding of connections within and across systems;

- Guiding questions (what changes? how does it change? why does it change?);

○ Connection keywords that help students think like "scientists thinking about and discovering earth-system connections";

- Causes, effects;

- Increases, decreases;

- Changes, impacts.

In the ESS model, as an Event is entered, it can then be understood in terms of its relationships to each of earth's spheres, as in the following diagram (see Figure 1).

Figure 1. Event-sphere connections. Illustration courtesy of Exploring the Environment ${ }^{\circledR}$ (http://ete.cet.edu).

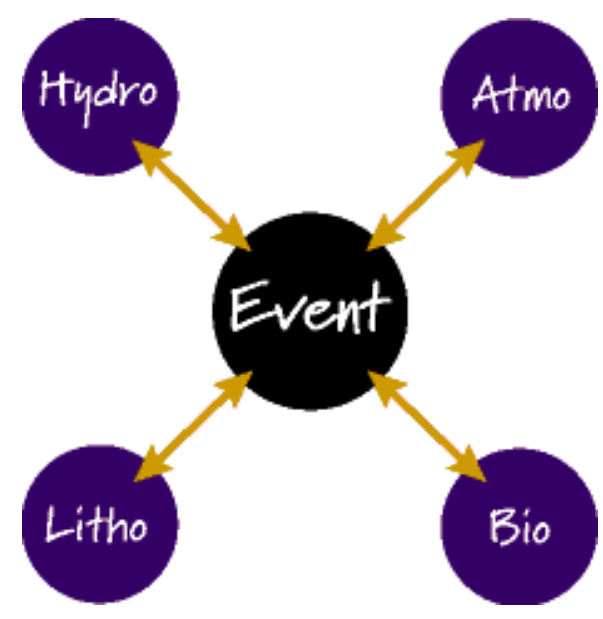


Over time, and with increasing sophistication and child cognitive development, increasing connections can then begin to be made (see Figure 2).

Figure 2. Elaborated event-sphere connections. Illustration courtesy of Exploring the Environment ${ }^{\circledR}$ (http://ete.cet.edu).

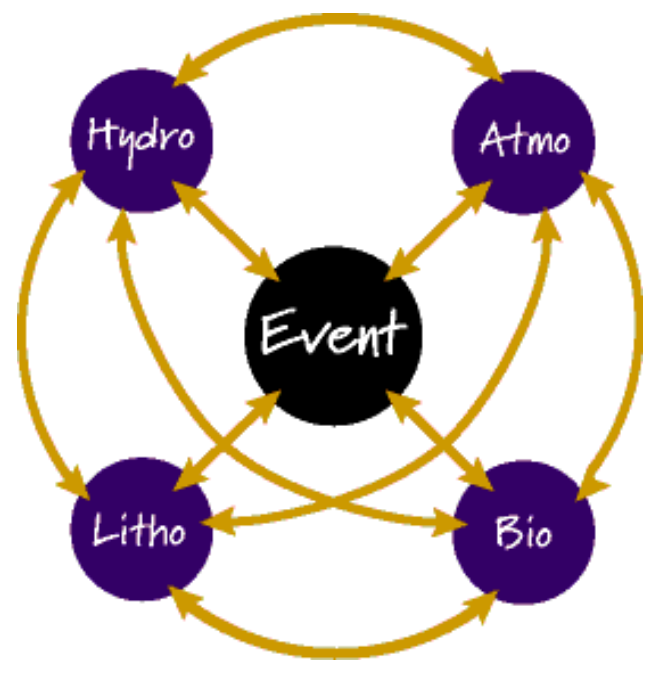

Building on and extending the ESS model, an additional node can then be added to link earth systems and the event with human systems (see Figure 3).

Figure 3. Event-earth-human systems connections.

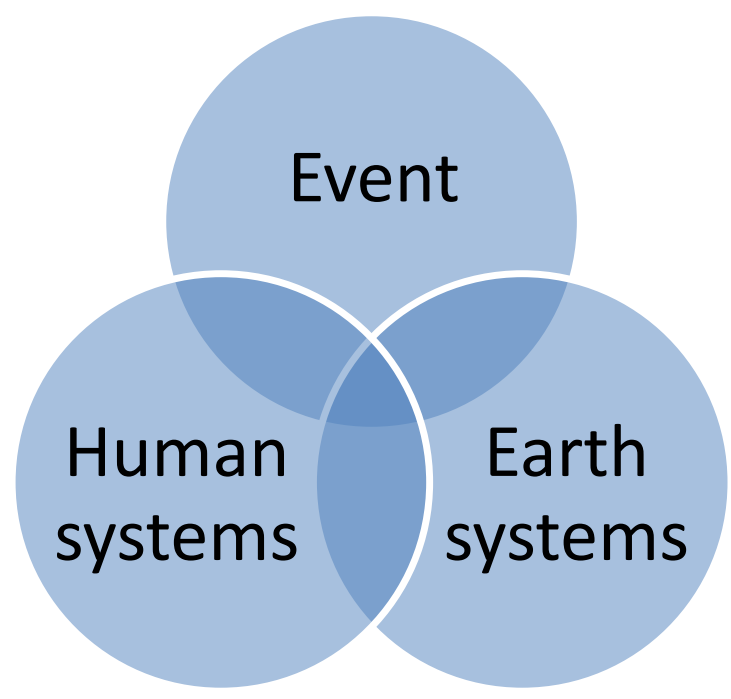

Filling in the human systems node can include a number of systemic strategies that are process- or structurally-based. One type of process model would take account from prior to the event through to following the event and be able to delineate resilient versus vulnerable pathways. This could be quite specific pathways linked to natural hazard events specifically or more generally delineating resilient versus vulnerable "risk and uncertainty" pathways. This could then be accompanied by guiding questions and connection keywords to help students understand vulnerable versus resilient pathways and how one is more likely to be on one pathway versus another. These guiding questions and connection keywords could be drawn from those of the ESS model: 
(1) What changes are related to being on risk versus resilient pathways?

(2) How and why does change happen to be on one path versus the other?

(3) Connection keywords:
a. Causes, effects;
b. Increases, decreases;
c. Changes, impacts;
d. Parts, parts-whole.

A more structural human systems model would delineate between different human systems, making links between them similar to the ESS's event-spheres diagram. This structure could be anything from individual- to more community-level focused and become increasingly sophisticated over time, congruent with children's development and increasing understanding. Thus, for younger children, connections could be made to help them understand themselves and their families more systemically. Thus, an event (e.g., storm with high winds) could first be understood in terms of child nodes (thoughts, behaviours, feelings, bodily reactions). Over time, with increasing development, they could then be further connected to "outside the child" nodes (e.g., schools node, friends node, "family and home" node). Thus, as the child develops more mature thinking (see next section), more community-level models can start to be introduced. For example, Norris and colleagues [29] have a community-based model that has four main nodes: economic development, social capital, community competence, information and communication. While Norris et al. developed their model in relation to disasters, these main nodes have more general application. Each node can have any number of sub-nodes in relation to a particular event being mapped. In terms of promoting resilience to disasters, the sub-nodes that Norris [56] emphasises are the following:

- Economic development;

- Resource level;

○ Resource equity;

○ Resource diversity.

- Social capital;

○ Social support and networks;

- Social participation;

○ Bondedness and commitment to the community.

- Information and communication;

- Trusted sources of information that are linked together;

- Responsible media;

○ Good information infrastructure.

- Community competence;

- Collective sense of control and efficacy;

- Sense of empowerment;

- Collective and cooperative decision-making and actions. 
Reflecting systems thinking, Norris herself states that "resilience to disaster... rests not only or even primarily on traditional preparedness activities but on building economically strong communities whose members can work together and use information to make decisions and act" [56]. In moving to systemic educational approaches, Ronan and Johnston's Strengthening Systems (SS4R) model ([2]; see also [3]) emphasizes an educational platform involving the strengthening of relationships through "spreading activation networks" within communities. An important network in any given community is the school-youth-household network, one that generally involves the majority of residential households.

\subsubsection{Starting Simple and Building over Time: Stages, Modes of Learning, Problem-Solving Tools}

Helping children move to a systems- and community-level understanding of how to manage risk and uncertainty in relation to natural hazards and other events needs by necessity to start at the basic in younger years. When children are aged 5-6, they are typically in the pre-operational level of cognitive development, a time characterized by egocentrism and "perceptual centering" [57]. Thus, they are incapable of understanding problems in more adult, systemic ways and require an approach that appeals to their capacity and their lifeworld. Starting simple, a sequenced approach then can keep pace with the child's growing competencies and add more complexity over time. Thus, it can help move disaster preparedness, and related, education along a developmental continuum that helps children begin to develop basic understandings of uncertainty, risk and risk mitigation first from a child-focused and family perspective and ultimately to a community-level focus. This should start with simple ideas for younger children in early school years (i.e., from age 5-6). Simple ideas can then be elaborated to develop an increasingly sophisticated understanding of the science linked to physical and human systems. In teaching the science of hazards and disasters, it is worthwhile to help children also understand that increased understanding and knowledge is also linked to increased "solutions" (e.g., increased willingness to engage in risk reduction activities and an increased sense of control [5,26,27]).

Children at school entry level need to be taught about hazards at their level of understanding: first through simple scientific knowledge (e.g., floods happen because rain can cause waterways to rise). Second, a related emphasis would include helping them learn that hazards can be managed in ways that children at these ages would understand and appreciate. In particular for children at this developmental stage, it would focus on promoting increased safety. Thus, levees get in the way of rising water and can keep people safe, installing home alarms can detect smoke and help people get out of a burning building and bringing a safety plan home to fill out with parents can "help keep me and my whole family safe."

As children start to enter concrete operations from about age 7 [57], they are better able to accommodate the seeds of systemic thinking, including thinking in more relational terms (e.g., conservation). Thus, scientifically-based connections can help children begin to understand that a solution can also have a drawback. A built levee can solve one problem (protecting communities) while introducing another that can be described, discussed, and even demonstrated (e.g., downstream flooding). Additionally, a self-help, safety metaphor used with younger children can begin to increasingly incorporate a "good citizenship" focus that also develops during this stage of development, including basic links to nodes in models such as the Norris et al. model described earlier. This could include basic depictions of numerous modes that appeal to and encourage a civics-based mindset, part of the 
growing lifeworld at this stage of development (e.g., community participation and bondedness; responsible and trusted information networks that work together; working together to make cooperative decisions to help those in a community). One example of a civics-related problem might be learning about complacency around preparedness. This problem can be like other problems linked to both the science of flooding (e.g., flood return periods; structural integrity of levees) and human factors (e.g., levees can discourage additional home-based adjustment activities based on the perception of a levee as a "cure all"). Solutions can then be problem-solved through various classroom and teaching modes (e.g., brainstorming, discussion, homework exercise with parents; community motivational exercise; see also below).

In addition, as children begin to be able to think in more logical, relational terms, systemic thinking approaches can also start to be introduced. For example, there are events to think about in terms of their parts (analytic thinking; how things are different) and there are connections between events in terms of how they work together (synthetic thinking; how things are the same) (Given a systemic model favouring a combination of analytic and synthetic approaches, helping children start to develop a systemic mindset can involve helping them think in terms of both differences and similarities. This could start with simple concrete objects or living things (e.g., dog and cat, how are they different? how are they the same?). Over time, more sophisticated approaches can then be introduced (e.g., posing a problem and then asking for different solutions; writing solutions on the board and asking how are individual solutions different from each other but also how are they the same? Sometimes the best answer to a problem is a singular solution, sometimes a more synthetic solution that cuts across different possibilities). Over time, these can incorporate hazards- and risk-related topics).

As children continue to advance cognitively, and move to the stage of being able to think more conceptually, other problems that appeal to a more adolescent, formal operational level of thinking [57] might be introduced. Of many possibilities, one example is social justice (e.g., those who typically live in flood plains, and near levees that may or may not be well maintained, can also be from more vulnerable sectors of society (e.g., Ward 9, New Orleans in Hurricane Katrina)). Another set of topics might draw on social science findings [10,11,29,56,58,59] and discuss and problem-solve around the idea that those who do prepare effectively at the individual and household level might nevertheless continue to be at risk of other unanticipated community-level impacts (e.g., vicarious trauma; economic effects; social cohesion that can be accompanied or followed by elements of polarization and breakdown).

To summarise the foregoing discussion, a systems approach would link up the value of an increasingly sophisticated understanding of the science of hazards with social factors, starting with simple self-help strategies at earlier ages and increasingly sophisticated community- and civic-minded problems, views and actions at later ages. With advancing age, children begin to enter the concrete operational stage of thinking (from ages 7-8 [57]), and the increasing ability to consider different dimensions of a problem (i.e., moving from "perceptual centredness" on one aspect of a problem to "decentering" and the ability to consider different elements of a problem simultaneously). At about this age, the relationship between self-help and community-focused actions can be introduced and considered. With advancing age and development, more complexities can then be added (e.g., community complacency; social justice; economic implications). Alongside and as part of this approach, helping children understand that helping oneself and collectively helping others can have numerous 
benefits, including reduced physical, socio-emotional and financial/economic impacts at both the individual and community levels. In addition, helping oneself and "collective helping" have been shown to lead to other more generalisable benefits, including positive feelings and an increased sense of mastery, efficacy, control, and connectedness [2,41,59]. In fact, at more advanced ages (high school), the link between collective helping and problem-solving can be illustrated by a discussion of research that suggests that policies that are developed through collaborative strategies versus other means (e.g., authoritative or competitive strategies) are thought to be more effective for solving wicked problems linked to risk and other complex problems [33], including disasters and in educational contexts [60].

To supplement learning in the classroom, discussion points, examples, simulations and a variety of in- and out-of-class experiential learning approaches can be used. Selby and Kagawa's [28] mapping of disaster risk reduction approaches in school curricula in 30 countries highlight numerous types of interactive learning that have been used to date. (These include "various forms of interactive learning (brainstorming as well as pair, small group and whole group discussion on disaster risk/climate change topics); inquiry learning (team case study research, internet searches, project work); surrogate experiential learning (filmic experience, board games, plays, drama, simulations on disasters and climate change; field experiential learning (field visits to disaster support services, hazard mapping, vulnerability assessment in school and community, community hazard transects and surveys); action learning (poster campaigns, street theatre around disasters and climate change, holding public meetings, risk reduction campaigns and projects, such as tree planting)" (p. 214) [47]).

Whatever the form of interactive learning, helping with increased connectivity to the home and to the community would assist as would connections between scientific and social/societal aspects. This might include working through known examples of problems linked to disaster risk reduction and response. For example, drawing on both flood and fire examples from earlier, the opportunities, and opportunity costs, linked to flood levees and to fire safety could be used to help connect the science with an increasing set of risk reduction competencies, which range from simple and safety-focused at young ages to more systemic and connected at older ages. To assist teachers, published "case examples" here are available in relation to levees (e.g., New Orleans) [33] and in relation to fire safety in Australia [35-38] and Surrey, British Columbia [40,61]. In the case of the latter, the case study of Surrey not only speaks to systemic issues related to fires and fire safety, it also presents research around solving some of those problems through an interactive, community-level campaign [61] that was based on an evaluation of systemic problems identified [40]. Such case examples could be drawn from, with material adjusted to the age level of the child, and used to frame a problem that then is turned over to students to solve.

As part of this process, more simple problem-solving tools can be introduced at younger ages with more advanced ones introduced over time (This might include a basic problem-solving sequence for younger children that defines the problem in basic terms: what choices are available to solve the problem, consequences for each choice, choosing of best alternative (e.g., family emergency plan). Over time, rather than simply choosing one alternative as is usually done, an emphasis on increasingly synthetic, systemic solutions can start with brainstorms for a large number of alternatives and then help children start to find the themes that cut across these alternatives (e.g., combination of prevention strategies in the home with more community-focused, collective solutions). Additionally, as children 
get more towards adolescence, more systemic problem-solving tools can start to be introduced to build on the more simple problem-solving approach. For example, the theory of constraints [62] adds questions to a problem-solving process such as what to change? what to change it into?; how to bring about change and then sustain and improve on it?; why change? In this model, a number of more specific tools are also available (e.g., evaporating cloud; core conflict cloud, future reality tree; positive reinforcement loop). Numerous other approaches and tools are also available [63]).

In flood (New Orleans), fire (Australian, Surrey) or other examples, students could have a "go" at problem solving pitched at the appropriate age level (e.g., young ages, how do we protect ourselves in our home?; older ages, how do we protect ourselves and others in our community and why are both important?) that is complemented with discussion, argument, identification of problem themes and solutions that have agreed upon value. Then, elements of the "solution" (e.g., from Surrey example) can be presented and discussed, including "what else could be done here?" Following case examples, attention could then be turned to a local problem related to some risk, hazards or otherwise, that uses a similar process and incorporates experiential learning including interactive efforts to motivate households and a community to act.

On the issue of motivation, it is an essential issue in preparedness for disasters given universally low levels of preparedness including in high hazard areas [6]. One reason of course is complacency, based on competing priorities or low levels of risk perception. In relation to risk more generally, risk perceptions have been found to motivate protective behaviours in the public but have also been found to have a negative relationship (i.e., promote avoidance [64]). Thus, a perception of risk, particularly higher levels, can invite for some negative emotions like fear and anxiety. High anxiety and its link to avoidance behaviour is well-established [65]. Anxiety has also been related to higher levels of perceived risk [66]. Children with higher levels of fear have been found to have lower hazards knowledge [4] and increased perceptions of not being prepared [27]. Recall also the finding that family settings with highly anxious children tend to have adults with similar problems, including a family environment that supports avoidant solutions to problems [16]. Thus, if anxiety, or "risk concern", is too low or high, it can motivate avoidant behaviour or inhibit approach behaviour, consistent with a well-known maxim in psychology called the Yerkes-Dodson law [67]. By contrast, moderate levels of anxiety or concern invite the adaptive features of that emotional state, inviting increased willingness to engage in behaviours to solve problems and to engage in behaviours that successfully solve those problems. As introduced earlier, then, framing hazards as challenges versus threats [48] would be thought to help invite the pattern of arousal and accompanying cognitive and behavioural readiness that promotes consideration of change and actual change behaviours. However, motivation is more than challenge versus threat perceptions. In addition, owing to the critical role of motivation in preparedness, a more explicit focus on its role in a systems educational approach is warranted.

\subsubsection{The Role of Motivation in Systemic Education and Risk Management}

A simple view of behaviour change of any sort reflects two main elements, (1) competencies necessary to enact change (knowledge and skills) that is (2) "fuelled" through emotional factors (Psychology textbooks include in their definition of emotions the idea of emotions as "behavioural tendencies". That is, a primary function of emotion is to motivate particular types of behaviour [65]). 
That fueling function is generally referred to as motivation. For any change behaviour, it assumes that a person "can do" the behaviour (i.e., has competence to think through and perform the behaviour) but it also assumes that a person wants to carry out some behaviour, the "will do" factor.

According to the motivational interviewing (MI) model, Miller and Rollnick [68] extend the can do and will do ideas to a sequence that emphasises being "willing, able, and ready" to make change. Willingness to change is tied to one's emotional investment. In terms of the can do or ability factor, this represents an individual's capacity and sense that a behaviour itself (e.g., hazard preparedness activity) can be effective (general efficacy), alongside confidence that they are able to carry out the behaviour (self-efficacy) [20]. The "ready" factor reflects the idea that changing behaviour now is better than doing it later.

The MI model focuses on the idea of "developing discrepancy" as part of the process to increase one's willingness to consider change. The idea is to create a noticeable discrepancy between one's current status and a value or a goal state. The more the discrepancy, the greater potential for motivation and the carrying out of some change behaviour, Representing an underlying philosophy that is relational (versus split) [43], there is a connection (i.e., a relationship) drawn between a current state of affairs and its degree of discrepancy from an imagined future. The "discrepancy space" itself represents motivational space. Thus, the idea of helping people "develop and amplify" discrepancy is intended to elicit motivation. Motivation that is intrinsic (from within) versus extrinsic (e.g., "I need to prepare because my teacher tells me I have to") is the focus here (In terms of hazards mitigation, it is worth noting that we also favor extrinsic motivation (e.g., mandated land use planning, building codes and so forth). Mandated activities can co-exist with voluntary activities that children and families can adopt to help them protect themselves and their households in the event of a major hazardous event, mindful that regulation in relation to hazardous events comes with opportunities, opportunity costs, tipping points and so forth [36]).

As a discrepancy is first widened through discussions, it can then be "resolved" through "change talk." This can include consideration of the advantages (and disadvantages) of change and begin to promote change talk that has increasing "commitment strength". Increasing commitment strength can then help a person, classroom, or community to move along in the "stages of change" continuum [69]. Support for a motivational approach in the hazards preparedness literature has come from research that implicates increased motivation as key to initiating change (see review [3]). Thus, disaster preparedness education programs can include such discussions to help motivate children while at the same time providing them with a set of motivational tools for use in other contexts.

Preparedness education programs that introduce the idea of hazards and risk as challenges versus threats can also incorporate "discrepancy tools" to help children work from a current state of affairs to a more desirable future, including delineating vulnerable versus resilient pathways to the future. As part of that process, it could then further help them begin to learn about problems (i.e., current state of affairs) through a systemic and scientific understanding and then be able to picture and map an imagined future. Then, with the assistance of problem-solving tools, children can then begin to discuss and map out movement from present to future, mindful in the case of wicked problems [33] that the process quite often is non-linear.

As a result, as children develop more mature thinking, this process should include the idea that problems related to risk tend to get more effectively solved with holistic solutions: Ones that take 
account of both physical and human systems, employ systemic thinking strategies, use collaborative problem-solving, and so forth. Related to collaborative efforts, developing relationships and strengthening links between systems within a community would be thought to help develop a shared sense of motivation for both personal and collective action. This could of course include leveraging the school-youth-family network to initiate a community-wide focus on a problem. Thus, as children carry their learning, their motivation and growing sense of efficacy and mastery home with them, they can at the same time understand that schools and households are embedded in communities that are interconnected socially, occupationally, economically and in other ways. Helping them understand how to connect within a community would be thought to enhance their own learning while also potentially helping contribute to community-level competence, efficacy, and action. This can include for problems related to hazards preparedness and resilience [29] and a host of others. In other words, children can leverage their learning to help motivate their homes, and their communities, to act in important ways [2,47].

\section{Summary}

To summarise important ideas presented in this paper, in a systems educational approach, various concepts first taught on their own merits can become increasingly inter-connected over time including:

(1) That science, research, and increased understanding are basic tools to help deal with problems linked to risk and uncertainty in life;

(2) Linking various factors with each other including:

(a) Physical with human systems in relation to disasters and other risks;

(b) The child with the home, the home with the community, the community within a region, the region within a country and so forth;

(c) Preparedness activities with more effective response and recovery;

(d) Physical preparedness and response with psychosocial preparedness and response; linking risk mitigation with living within a world of others;

(e) The idea of learning and behavioural change with emotional factors (e.g., motivation, confidence, sense of one's efficacy); linking knowledge and skills (e.g., increased physical preparedness) with increased confidence and sense of control that can assist quality decision-making under duress;

(f) Preparedness for hazards with the larger theme of developing the knowledge, skills, motivation and self-efficacy to underpin a growing holistic ability to think through and solve problems in life linked to risk and uncertainty;

(3) That managing risk and uncertainty can have both local solutions (e.g., a sense of personal responsibility; preparedness at home) and wider systemic solutions (e.g., increased community development, linkages, and collective helping; land use planning; policy development and practices that understand opportunities, opportunity costs, tipping points, relationships between various physical and human systems). 
With respect to preparedness education currently, most education programs focus on fairly simple themes related to "what you and your family can do to keep safe". While this is definitely a useful starting point, particularly for younger children, a systems perspective would go beyond that to help children develop an increasingly sophisticated understanding of the context of natural hazards. This includes complexities linked to this particular wicked problem. One main one is that human beings are part of the disaster cycle, not just passive recipients. We are part of the problem as well as part of the solution. Consistent with ideas linked to the UNISDR's CC-DRR approach [28], it can help children and adolescents become increasingly empowered with knowledge and skills that hazard events are challenges that can be approached versus avoided.

We see interactive components of education programs as one of their greatest strengths. As findings from our own research program have demonstrated, linking children's learning and enthusiasm with the family and home preparedness has potential in terms of both physical preparedness and emotional readiness. However, this link certainly merits extending beyond the school-youth-family network to the wider community [24]. Initiatives to promote increasing connectedness include collaborative networking between schools and others in a community [2]. These discussions have potential for increasing the discrepancy between the current status (e.g., low preparedness within the community) and an ideal status or goal, the increased protection of that local community (including its children) from those local hazards that threaten it. An area for future research is assessing the added value of preparedness education in schools as part of a larger community-based campaign (Our team is starting a three year project, 2014-2016, in the area of CC-DRR, funded by Australia's Bushfire and Natural Hazards Cooperative Research Centre. In particular, this project aims to inform practice, policy and research first through a large scale review and scoping process followed by development and evaluation of hazards education programming for children. One aim of this project is to move preparedness education programs to more systemic models as discussed in this paper. This includes linking preparedness education to community-level initiatives and solutions).

As it relates to children and families, and their increased risk status, such initiatives may well create road maps for a planned and effective household response to a disaster that includes linkages to larger community efforts. A systems approach to preparedness education can also promote outcomes for children that help them become increasingly effective, confident systems thinkers and doers and as they move towards adulthood. Those who are able to deal with specific problems like natural hazards but, equally, are also willing, able and ready to deal with a range of challenges that life presents.

\section{Acknowledgments}

The preparation of this paper was supported in part through funding from the Australian Bushfire and Natural Hazards Cooperative Research Centre and from the New Zealand Government in association with the Natural Hazards Research Platform.

\section{Author Contributions}

Both authors made contributions to this paper in accord with order of authorship. Kevin Ronan wrote the majority of the paper while Briony Towers contributed through adding her own expertise in 
working with children to each of the major sections of the manuscript to supplement, extend, provide an alternative view to early drafts.

\section{Conflicts of Interest}

The authors declare no conflict of interest.

\section{References}

1. Nguyen, N.; Bosch, O. The art of interconnected thinking-Starting with the young. Systems 2014, in press.

2. Ronan, K.R.; Johnston, D.M. Promoting Community Resilience in Disasters: The Role for Schools, Youth, and Families; Springer: New York, NY, USA, 2005.

3. Ronan, K.R.; Crellin, K.; Johnston, D.M.; Finnis, K.; Paton, D.; Becker, J. Promoting child and family resilience to disasters: Effects, interventions, and prevention effectiveness. Child. Youth Environ. 2008, 18, 332-353.

4. Ronan, K.R.; Johnston, D.M.; Daly, M.; Fairley, R. School Children's Risk Perceptions and Preparedness: A Hazards Education Survey. Available online: http://www.massey.ac.nz/ trauma/ issues/2001-1/ronan.htm (accessed on 8 October 2013).

5. Ronan, K.R.; Johnston, D.M. Correlates of hazard education programs for youth. Risk Anal. 2001, 21, 1055-1063.

6. Lindell, M.K.; Arlikatti, S.; Prater, C.S. Why people do what they do to protect against earthquake risk: Perceptions of hazard adjustment attributes. Risk Anal. 2009, 29, 1072-1088.

7. Mileti, D.S.; Darlington, J.D. The role of searching in shaping reactions to earthquake risk information. Soc. Probl. 1997, 44, 89-103.

8. Ollendick, T.H. Reliability and validity of the Revised Fear Survey Schedule for Children (FSSC-R). Behav. Res. Ther. 1983, 21, 685-692.

9. Ollendick, T.H.; Matson, J.L.; Helsel, W.J. Fears in children and adolescents: Normative data. Behav. Res. Ther. 1985, 23, 465-467.

10. Burnham, J.J.; Hooper, L.M.; Edwards, E.E.; Tippey, J.M.; McRaney, A.C.; Morrison, M.A.; Underwood, J.A.; Woodroof, E.K. Examining children's fears in the aftermath of Hurricane Katrina. J. Psychol. Trauma 2008, 7, 253-275.

11. Norris, F.H.; Friedman, M.J.; Watson, P.J.; Byrne, C.M.; Diaz, E.; Kaniasty, K. 60,000 disaster victims speak: Part I. An empirical review of the empirical literature, 1981-2001. Psychiatry 2002, 65, 207-260.

12. Ronan, K.R. The Effects of a "Benign" Disaster: Symptoms of Post-Traumatic Stress in Children Following a Series of Volcanic Eruptions. Available online: http://www.massey.ac.nz/ trauma/ issues/1997-1/ronan1.htm (accessed on 8 October 2013).

13. Hock, E.; Hart, M.; Kang, M.J.; Lutz, W.J. Predicting children's reactions to terrorist attacks: The importance of self-reports and pre-existing characteristics. Am. J. Orthopsychiatr. 2004, 74, 253-262.

14. Huzziff, C.A.; Ronan, K.R. Prediction of Children's Coping Following a Natural Disaster-The Mount Ruapehu Eruptions: A Prospective Study. Available online: http://trauma.massey.ac.nz/ issues/1999-1/huzziff1.htm (accessed on 8 October 2013). 
15. Ronan, K.R. The effects of a series of volcanic eruptions on emotional and behavioural functioning in children with asthma. N. Z. Med. J. 1997, 110, 11-13.

16. Dadds, M.R.; Barrett, P.M.; Rapee, R.M.; Ryan, S. Family process and child anxiety and aggression: An observational analysis. J. Abnorm. Child Psychol. 1996, 24, 715-734.

17. Siqueland, L.; Kendall, P.C.; Steinberg, L. Anxiety in children. J. Clin. Child Psychol. 1996, 25, 225-237.

18. Karanci, N.; Aksit, B.; Dirik, G. Impact of community disaster awareness training program in Turkey: Does it influence hazard-related cognitions and preparedness behaviors. Soc. Behav. Personal. 2005, 33, 243-258.

19. Kelly, B.; Ronan, K.R. Engaged versus passive public education for disaster preparedness. 2014, submitted for publication.

20. Paton, D. Disaster preparedness: A social-cognitive perspective. Disaster Prev. Manag. 2003, 12, doi:10.1108/09653560310480686.

21. Peek, L. Children and disasters: Understanding vulnerability, developing capacities, and promoting resilience-An introduction. Child. Youth Environ. 2008, 18, 1-29.

22. Johnson, V.A.; Ronan, K.R. Evaluations of disaster education programs for children: A methodological review. 2014, unpublished work.

23. Ronan, K.R.; Crellin, K.; Johnston, D.M. Community readiness for a new tsunami warning system: Quasi-experimental and benchmarking evaluation of a school education component. Nat. Hazards 2012, 61, 1411-1425.

24. Shaw, R.; Shiwaku, K.; Kobayashi, H.; Kobayashi, M. Linking experience, education, perception, and earthquake preparedness. Disaster Prev. Manag. 2003, 13, 39-49.

25. Ronan, K.R.; Crellin, K.; Johnston, D.M. Correlates of hazards education for youth: A replication study. Nat. Hazards 2010, 53, 503-526.

26. Ronan, K.R.; Johnston, D.M. Hazards education for youth: A quasi-experimental investigation. Risk Anal. 2003, 23, 1009-1020.

27. Webb, M.; Ronan, K.R. A quasi-experimental investigation of a hazards education program for youth in a low SES community. 2014, submitted for publication.

28. Selby, D.; Kagawa, F. Disaster Risk Reduction in School Curricula: Case Studies from Thirty Countries. Geneva/Paris: UNICEF/UNESCO, 2012. Available online: http://www.educationand transition.org/resources/unicefunesco-mapping-of-global-drr-integration-intoeducation-curriculasustainability-frontiers/ (accessed on 8 October 2013).

29. Norris, F.; Stevens, S.P.; Pfefferbaum, B.; Wyche, K.; Pfefferbaum, R.L. Community resilience as a metaphor, theory, set of capacities, and strategy for disaster readiness. Am. J. Community Psychol. 2008, 41, 127-150.

30. Johnson, V.A.; Ronan, K.R. Experiences of New Zealand school teachers and displaced children following the 2011 Christchurch Earthquake. Nat. Hazards 2014, in press.

31. Helbing, D. Globallly networked risks and how to respond. Nature 2013, 497, 51-59.

32. Salmon, P.M.; Goode, N.; Archer, F.; Spencer, C.; McArdle, D.; McClure, R. New perspectives on disaster response: The role of systems theory and methods. In Proceedings of the Australian and New Zealand Disaster and Emergency Management Conference, Brisbane, Australia, April 2012; pp. 353-367. 
33. Australian Public Policy Commission. Tacking Wicked Problems: A Public Policy Perspective; Commonwealth of Australia: Canberra, Australia, 2007.

34. Adams, V.; van Hattum, T.; English, D. Chronic disaster syndrome: Displacement, disaster capitalism, and the eviction of the poor from New Orleans. Am. Ethnol. 2009, 4, 615-636.

35. Ashe, B.; Macaneney, K.J.; Pittman, A.J. Total cost of fire in Australia. J. Risk Res. 2009, 12, 121-136.

36. Ashe, B.; de Oliveira, F.D.; McAneney, J. Investments in fire management: Does saving lives cost lives? Agenda 2012, 19, 89-103.

37. Ashe, B.; Macaneney, K.J.; Pittman, A.J. Is the allocation of resources towards mitigation and response to fire in Australia optimal? J. Risk Res. 2011, 14, 381-393.

38. Brennan, P. Victims and survivors in fatal residential building fires. Fire Mater. 1999, 23, 305-310.

39. Crompton, R.P.; McAneney, K.J.; Chen, K.; Pielke, R.A.; Haynes, K. Influence of location, population and climate on building damage and fatalities in Australian bushfire: 1925-2009. Weather Clim. Soc. 2010, 2, 300-310.

40. McCormick, A.V. Residential Fires in Surrey BC, 1988-2007; School of Criminology and Criminal Justice, University of the Fraser Valley: Abbotsford, BC, Canada, 2009.

41. Ben-Zur, H. Coping, affect and aging: The roles of mastery and self-esteem. Personal. Individ. Differ. 2002, 32, 257-372.

42. Pepper, S. World Hypotheses; University of California Press: Los Angeles, CA, USA, 1942.

43. Overton, W.F. A coherent metatheory for dynamic systems: Relational organicism-contextualism. Hum. Dev. 2006, 50, 154-159.

44. Fortuin, K.P.J.; van Koppen, C.S.A.; Kroeze, C. The contribution of systems analysis to training students in cognitive interdisciplinary skills in environmental science education. J. Environ. Stud. 2013, 3, 139-152.

45. Smith, C.A.; Kirby, L.D. Putting appraisal in context: Toward a relational model of appraisal and emotion. Cognit. Emot. 2009, 23, 1352-1372.

46. Chapman, J.D.; Aspin, D.N. A problem-solving approach to addressing current global challenges in education. Br. J. Educ. Stud. 2013, 61, 49-62.

47. Kagawa, F.; Selby, D. Ready for the storm: Education for disaster risk reduction and climate change adaptation and mitigation. J. Educ. Sustain. Dev. 2012, 6, 207-217.

48. Blascovich, J. Challenge and Threat. In Handbook of Approach and Avoidance Motivation; Elliot, A.J., Ed.; Psychology Press: New York, NY, USA, 2008; pp. 431-445.

49. Frings, D.; Hurst, J.; Cleveland, C.; Blascovich, J.; Abrams, D. Challenge, threat, and subjective group dynamics: Reactions to normative and deviant group members. Group Dyn. Theory Res. Pract. 2012, 16, 105-121.

50. Blascovich, J.; Mendes, W.B.; Seery, M. Intergroup Threat: A Multi-Method Approach. In From Prejudice to Intergroup Emotions: Differentiated Reactions to Social Group; Mackie, D.M., Smith, E.R., Eds.; Psychology Press: New York, NY, USA, 2002; pp. 89-109.

51. Blascovich, J.; Mendes, W.B. Challenge and Threat Appraisals: The Role of Affective Cues. In Feeling and Thinking: The Role of Affect in Social Cognition; Forgas, J.P., Ed.; Cambridge University Press: New York, NY, USA, 2000; pp. 59-82.

52. Oppenheimer, J.E. Understanding Early Vulnerabilities for Anxiety: Predictors of Self-Efficacy in Toddlers. Unpublished Ph.D. Dissertation, University of Oregon, Eugene, OR, USA. 
53. Swann, J. Learning, Teaching and Education Research in the 21st Century; Continuum: London, UK, 2011.

54. Earth System Sciences Committee (ESSC). Earth System Science: A Program for Global Change; NASA: Washington, DC, USA, 1988.

55. Gagnon, V.; Bradway, H. Connecting earth systems: Developing holistic understanding through the Earth-System-Science model. Sci. Scope 2012, 36, 68-76.

56. Norris, F.H. Capacities that promote resilience. Plenary presentation: What makes a resilient community. In Proceedings of the Fourth Annual Department of Homeland Security Network Summit, Washington, DC, USA, March 2010.

57. Lerner, R. Concepts and Theories of Human Development, 3rd ed.; Lawrence Earlbaum: Mahwah, NJ, USA, 2002.

58. Kemmelmeier, M.; Broadus, A.D.; Padilla, J.B. Inter-group aggression in New Orleans in the immediate aftermath of Hurricane Katrina. Anal. Soc. Issues Public Policy 2008, 8, 211-245.

59. Drury, J. Collective Resilience in Mass Emergencies and Disasters: A Social Identity Model. In The Social Cure: Identity, Health and Well-Being; Jetten, J., Haslam, C., Haslam, S.A., Eds.; Psychology Press: New York, NY, USA, 2012.

60. Tong, T.M.T.; Shaw, R.; Takeuchi, Y. Climate disaster resilience of the education sector in Thua Thien Hue Province, Central Vietnam. Nat. Hazards 2012, 63, 685-709.

61. Clare, J.; Garis, L.; Plecas, D.; Jennings, C. Reduced frequency and severity of residential fires following delivery of fire prevention by on-duty fire fighters: Cluster randomized controlled study. J. Saf. Res. 2012, 43, 123-128.

62. Goldratt, E.M.; Cox, J. The Goal: A Process of Ongoing Improvement; North River Press: Great Barrington, MA, USA, 2004.

63. Dettmer, H.W. The Logical Thinking Process: A Systems Approach to Complex Problem Solving; ASQ Quality Press: Milwaukee, WI, USA, 2007.

64. Rimal, R.N. Perceived risk and self-efficacy as motivators: Understanding individuals' long-term use of health information. J. Commun. 2002, 51, 633-657.

65. Barlow, H.D.; Durand, V.M. Abnormal Psychology: An Integrative Approach, 5th ed.; Wadsworth/Cengage Learning: Belmont, CA, USA, 2009.

66. Chaffee, S.H.; Roser, C. Involvement and the consistency of knowledge, attitudes, and behaviors. Commun. Res. 1986, 13, 373-399.

67. Yerkes, R.M.; Dodson, J.D. The relation of strength of stimulus to rapidity of habit formation. J. Comp. Neurol. Psychol. 1908, 18, 458-482.

68. Miller, W.R.; Rollnick, S. Motivational Interviewing: Preparing People for Change; Guilford Press: New York, NY, USA, 2002.

69. Prochaska, J.O.; DiClemente, C.C.; Norcross, J.C. In search of how people change: Applications to addictive behaviors. Am. Psychol. 1992, 47, 1102-1114.

(C) 2014 by the authors; licensee MDPI, Basel, Switzerland. This article is an open access article distributed under the terms and conditions of the Creative Commons Attribution license (http://creativecommons.org/licenses/by/3.0/). 